\title{
Aspectos da anacorese na narrativa de Teodorico Raposo em $A$ Relíquia
}

\author{
Aspects of Anacoresis in Teodorico Raposo's Narrative in The Relic
}

\begin{abstract}
Resumo: Pensar sobre os processos de anacorese e de escrita de si a partir das obras de Eça de Queirós só é possível ao se buscar compreender o conjunto da obra queirosiana em seu contexto sociocultural de produção, terreno fértil e que apresenta suas diversas especificidades, ainda que alguns de seus aspectos tenham sido alvo da crítica afiada de Eça de Queirós. É apenas a partir desse viés cultural que os processos de anacorese e escrita de si tornam-se possíveis de serem pensadas na obra de Eça de Queirós, particularmente em O Mandarim, de 1880, e em A Relíquia, de 1887. Neste artigo, porém, o foco de análise estará em A Relíquia, a partir da personagem Teodorico Raposo. Como arcabouço teórico, foram utilizadas as especificidades do processo de anacorese e da escrita de si a partir da perspectiva teórica de Michel Foucault.
\end{abstract}

Palavras-chave: : Eça de Queirós; anacorese; escrita de si; Michel Foucault.

\begin{abstract}
Thinking about the processes of anacoresis and writing of self from the works of Eça de Queiroz is only possible when we try to understand the whole of Queirosian work in its socio-cultural context of production. This context was fertile ground with its various specificities, even though some of its aspects have been the target of Eça de Queiroz's criticism. It is only from this cultural aspect that the processes of anacoresis and self-writing become possible to analyze in Eça de Queiroz's work, particularly in The Mandarin of 1880, and The Relic of 1887. In this papaer, however, , the focus of analysis will be on The Relic, from the character Theodoric Raposo. As a theoretical framework, the specifics of the anacoresis process and the writing of self were used from Michel Foucault's theoretical perspective.
\end{abstract}

Keywords: Eça de Queiroz; anacoresis; writing of self; Michel Foucault.

\section{INTRODUÇÃO}

[...] a consciência é o juiz definitivo e autônomo das ações, é a fonte da independência do sábio. (MCKENZIE, 2003, p. 182).

Parafraseando Ítalo Calvino acerca da definição da obra clássica, os textos queirosianos, mesmo depois de um século, continuam suscitando novos e possíveis leituras, o que mantém viva as memórias e os posicionamentos críticos de Eça de Queirós,

\footnotetext{
${ }^{1}$ Este artigo é parte de pesquisa de doutorado, defendido em 2016, na Universidade de São Paulo - USP.

* Doutor em Literatura Portuguesa, professor da Universidade Estadual de Montes Claros - UNIMONTES.

E-mail: pcopmarciojean@gmail.com.
} 
tão necessários ás reflexões do mundo contemporâneo. Nessa perspectiva, pensar sobre os processos de anacorese e de escrita de si em Eça de Queirós só é possível quando se busca compreender o conjunto da obra de Eça a partir de seu contexto sociocultural, apresentando suas diversas especificidades ainda que alguns de seus aspectos sejam alvo da crítica afiada do autor d'As Farpas.

É apenas a partir desse viés cultural que os processos de anacorese e escrita de si tornam-se possíveis de serem pensadas na obra de Eça de Queirós, particularmente em $O$ Mandarim, de 1880, e em $A$ Relíquia, de 1887. Neste artigo, porém, o foco de análise estará em A Relíquia, a partir da personagem Teodorico Raposo. Antes, no entanto, faremos uma explanação acerca das especificidades do processo de anacorese e da escrita de si a partir da perspectiva teórica de Michel Foucault.

Nesse sentido, refletir sobre a personagem partindo do termo character, provindo da língua inglesa, parece ser muito apropriado para se pensar nas perspectivas dos cuidados e da escrita de si, abordados por Michel Foucault (1983), assim como também na forma espacial da personagem, discutida por Mikhail Bakhtin (2006). Isso porque character, que se traduz tanto como personagem como por caráter, em português, tem origem no latim e expressa a qualidade inerente a uma pessoa, ou seja, falar sobre a construção da personagem, nesse enfoque, significa falar sobre a formação do caráter da personagem.

No livro História da Sexualidade, publicado no ano de 1985, volume III, dedicado ao cuidado de si, no capítulo II, Michel Foucault se dedica a discutir a cultura de si buscando seus fundamentos no espaço privilegiado ao movimento ascético cristão que, já nos primeiros séculos, "apresentou-se como uma acentuação extremamente forte das relações de si para consigo, mas sob a forma de uma desqualificação dos valores da vida privada" (FOUCAULT, 1985, p. 48). Foucault, porém, havia detalhado melhor essa citação atribuída aos movimentos ascéticos da anacorese, em suas aulas públicas da disciplina Seminários Avançados IV, vindo a ser publicada no livro O que é um autor, em 1983, no qual dedicou um capítulo à discussão da escrita de si.

Em seu estudo, Michel Foucault procurou sustentar a tese de que é imprescindível que o indivíduo tenha cuidados consigo mesmo para, assim, poder se autoconhecer e garantir, também, a formação do caráter progressivamente. Essa busca de si para consigo prevê o relacionamento, a posteriori, com o outro, pelo exercício da alteridade. Ou seja, o indivíduo somente estará próximo de completar seu autoconhecimento quando for capaz de se conhecer e se reconhecer no outro, na sua alteridade.

Como já afirmara Alípio de Sousa Filho, no IV Colóquio Internacional Michel Foucault, no ano de 2007, todo pensamento de Foucault foi orientado pela concepção da negação do individual por exclusividade, o indivíduo não se constitui sozinho, mas com o outro. Segundo Sousa Filho, "Foucault inventa uma filosofia que liberta a nossa própria existência de nós mesmos ou da prisão de nossa 'subjetividade' que, social e historicamente construída, é, entretanto, vivida como uma substância natural e universal" (SOUSA FILHO, 2007, p. 4).

A busca de si, como se pode observar, começa no isolamento e se completa no encontro com o outro. Segundo Foucault, em História da Sexualidade III, "ao tomar a forma 
do cenobitismo, [a busca de si] manifestou uma recusa explícita daquilo que podia haver de individualismo na prática da anacorese.” (FOUCAULT, 1985, p. 48).

Foucault não para por aqui em sua argumentação e busca a Antiguidade Grecoromana para convalidar sua posição crítica. Com Xenofonte, Foucault justifica a necessidade do relacionamento interpessoal, o qual considera como sendo a realização plena do ser humano. Segundo Ciro, do qual Xenofonte traça o perfil:

Não podemos reprovar os deuses de não terem realizado todos os nossos desejos', diz ele pensando nas suas vitórias passadas, 'mas, se porque se realizou grandes coisas, não se pode mais ocupar-se consigo e alegrar-se com um amigo, essa é uma felicidade da qual me despeço com gosto (XÉNOPHON apud. FOUCAULT, 1985, p. 49, grifo nosso).

Dessa forma, de nada valeria possuir todo bem material e espiritual se esses forem uma condição de impedimento para a vivência da prática de ocupar-se consigo e com o outro. Assim sendo, fica claro, na perspectiva foucaultiana, como se dá a construção de si, ou seja, como se desenvolve a construção do caráter (do ser, da personagem), fazendo uso da perspectiva etimológica da palavra.

Em primeiro lugar, deve-se haver uma preocupação com o autoconhecimento, como uma prática de autodesalienação, seguido pelo convívio e discernimento da alteridade, respectivamente. Logo, a busca e os cuidados para consigo se constitui em um processo, um devir, por isso se desenvolve em meio a um processo doloroso de descobertas o que, em Foucault, se traduz como práticas de liberdade. Segundo Alípio de Sousa Filho (2007):

A liberdade-Foucault, olhando o poder por entre suas técnicas, e pelas frestas dos seus próprios mecanismos e dispositivos, definia as condições nas quais emergiria: (re)construindo o sujeito pelas artes do cuidado de si. Qual uma arte de luta, anuncia-se rivalizando com a sujeição: éticas do cuidado de si como prática de liberdade (SOUSA FILHO, 2007, p. 3).

Em Alcebíades, Sócrates demonstra a um ambicioso jovem o quanto seria presunçoso de sua parte querer dar conselhos a uma cidade e, ainda, rivalizar com os reis de Esparta ou com os soberanos da Pérsia se ainda não havia aprendido aquilo que seria necessário para saber governar, ou seja, deveria "primeiro, ocupar-se de si próprio - e logo, enquanto é ainda jovem, pois com 'cinquenta anos será demasiado tarde"' (Platão, Apud. FOUCAULT, 1985, P. 50).

Ao percorrer um longo caminho histórico e filosófico para justificar essa necessidade e eficácia da cultura de si, Foucault demonstra que essa cultura foi sendo transmitida de geração em geração, constituindo-se como prática social sendo que em algumas épocas acabaram sendo mais valorizadas que em outras (FOUCAULT, 1985, p. $50)$.

Essa prática social não está restrita às práticas religiosas, mas é um princípio válido a todas as pessoas e durante toda a vida, observa o filósofo mais adiante (Cf.: FOUCAULT, 1985, p. 53). Os epicuristas, por sua vez, aconselham "Que ninguém, sendo jovem, tarda a filosofar, nem velho se canse da filosofia. Pois para ninguém é demasiado 
cedo nem demasiado tarde para assegurar a saúde da alma" (Epicuro. Apud. FOUCAULT, 1985, p. 51).

Além de demonstrar como o cuidado de si se fez e se faz necessário em várias épocas, Foucault dedicou-se ainda a disponibilizar estratégias para o exercício da anacorese, tal como o exemplo dado por Marco Aurélio, na antiguidade, acrescida, porém, de uma síntese, com três elementos para formas específicas de exame e exercícios codificados.

Para Foucault, Marco Aurélio propõe um longo trabalho de resgate de princípios gerais e de argumentos racionais que persuadem a não deixar-se irritar com os outros nem com o acaso tampouco com as coisas, fazendo uso da prática de conversas confidentes com amigos, com um guia ou diretor, em que se pode expor o estado de sua própria alma, solicitar ou dar conselhos. A prática mútua de aconselhar é salientada na medida em que é vista, nesses exercícios aurelianos, como reatualização de conselhos para si próprio tanto ao dar quanto ao receber os conselhos (Cf.: FOUCAULT, 1985, p. 57).

Por outro lado, recorda Anderson Aparecido Lima da Silva, em sua pesquisa de mestrado, intitulada Michel Foucault: o sujeito moderno em questão, de 2013, que o sujeito não precisa, necessariamente, passar por uma transformação pessoal para que reconheça, ou seja, "o sujeito, por si só e sem que tenha que efetuar sobre si uma mudança em seu ser, tornou-se capaz de verdade" (SILVA, 2013, p. 37). Em outras palavras, uma das proposições de Foucault, que, aliás, ele legará a Descartes, é a de que o sujeito pode encontrar a verdade apenas se autoconhecendo, sendo quem ele realmente é. Segundo Foucault, em $A$ bermenêutica do sujeito, "não é o sujeito que deve transformar-se. Basta que o sujeito seja o que ele é para ter, pelo conhecimento, um acesso à verdade que lhe é aberto por sua própria estrutura de sujeito" (FOUCAULT, 2006, p. 171-172).

Outra proposição apresentada por Michel Foucault, porém, é a de que o conhecimento de si pode ser visto por aspectos espirituais. A partir desses aspectos, o sujeito deverá se transformar, "pagar" para ter acesso à verdade, ou seja, é preciso que ele se modifique, transforme-se:

[...] para a espiritualidade, um ato de conhecimento, em si mesmo e por si mesmo, jamais conseguiria dar acesso à verdade se não fosse preparado, acompanhado, duplicado, consumado por certa transformação do sujeito, não do indivíduo, mas do próprio sujeito no seu ser de sujeito (FOUCAULT, 2006, p. 17).

Porém, o sujeito deve manter-se em um constante exercício de conhecimento de si, visto que "A transformação de si jamais é definitiva, exigindo uma perpétua reconquista. Talvez seja esta uma das faces do 'preço' que o sujeito deve pagar para ter acesso à verdade na circunscrição da 'espiritualidade" " (SILVA, 2013, p. 40).

Acerca dessas informações, Silva (2013) chama a atenção para dois pontos que achamos pertinentes recuperar. O primeiro deles diz respeito aos aspectos "espirituais" e à "transformação de si" apontados por Michel Foucault em seus estudos. Tendo em vista que falar sobre espiritualidade, indubitavelmente, remete o leitor a aspectos religiosos, o que poderá induzir a interpretações errôneas do termo empregado, vale ressaltar seu uso no contexto dos cuidados de si apresentado Foucault. 
Anderson A. L. da Silva, em nota de rodapé, aponta que Michel Foucault havia lido com muito apreço o artigo de Pierre Hadot, publicado em 1977, intitulado "Exercises spirituaels et philosophie antique". No artigo em questão, Hadot emprega de diversas formas o termo "espiritual" e, conforme Silva, diversos "ecos" podem ser encontrados no curso de 1982, dado por Foucault no Collège de France. Nesse artigo o historiador Pierre Hadot justifica a escolha do termo do seguinte modo:

[...] "exercícios espirituais". A expressão desconcerta um pouco o leitor contemporâneo. Primeiramente não é mais de bom tom, hoje, empregar a palavra "espiritual". Mas é preciso se resignar a empregar este termo, porque os outros adjetivos ou qualificativos possíveis: "psíquico", "moral", "ético", "intelectual”, "de pensamento", "da alma" não recobrem todos os aspectos da realidade que queremos descrever. Poderíamos evidentemente falar de exercícios de pensamento, posto que, nestes exercícios, o pensamento se toma de alguma forma por matéria e procura a ele mesmo se modificar. Mas a palavra "pensamento" não indica de uma maneira suficientemente clara que a imaginação e a sensibilidade intervêm de uma maneira muito importante nestes exercícios. Pelas mesmas razões não podemos nos contentar com "exercícios intelectuais", mesmo que os aspectos intelectuais (definição, divisão, raciocínio, leitura, investigação, amplificação retórica) desempenhem um grande papel. "Exercícios éticos" seria uma expressão muito sedutora, visto que, nós veremos, os exercícios em questão contribuem fortemente à terapêutica das paixões e se relacionam à conduta de vida. Todavia seria ainda um ponto de vista muito limitado. De fato, estes exercícios correspondem a uma transformação da visão do mundo e a uma metamorfose da personalidade (HADOT Apud SILVA, 2013, p. 39).

Pode-se dizer que, por falta de outro termo que pudesse ser mais adequado, Foucault, assim como Hadot, emprega o termo “exercícios espirituais" à prática do conhecimento de si, já que esses exercícios correspondem a um amadurecimento do sujeito diante de seu mundo. Assim, uma nova visão de mundo e, por isso, uma nova personalidade é assumida e o sujeito é transformado.

Assim sendo, tomar parte dos exercícios espirituais como cuidados de si, implica uma busca incessante pela própria verdade, a verdade da essência do próprio sujeito para, a partir do seu encontro, buscar uma mudança de si.

A partir desse breve panorama acerca das práticas de si, apresentadas por Michel Foucault, é possível verificar como os exercícios de si estiveram e ainda está presente em diferentes culturas e épocas como prática social e como condição para o autoconhecimento e experiência de si.

\section{PROCESSOS DA ANACORESE EM TEODORICO RAPOSO}

Como exposto na introdução deste estudo e, em diálogo com a epígrafe apresentada anteriormente, refletir sobre si pressupõe um exercício de autoconhecimento; é o colocar a consciência como juiz das próprias ações e como fonte e busca da sabedoria. Logo, o autoconhecimento é um resgate das memórias passadas por intermédio de um filtro de julgamento a partir das experiências do presente; é um olhar de suprioridade e distanciamento que se lança aos acontecimentos passados. 
Partindo dessa reflexão inicial, passaremos ao estudo do romance $A$ Relíquia. que se desenvolve a partir das memórias de Teodorico Raposo. Logo no primeiro parágrafo, é possível identificar o discurso distanciado do narrador que relata suas memórias, assumindo a postura do narrador autodiegético do enredo.

Depois de ter ficado órfão, Teodorico vai viver com sua tia D. Patrocínio, senhora rica e muito religiosa. Por influência do Dr. Margaride, amigo da família, Teodorico aprende como se aproximar da tia e, assim, traça estratégias para herdar sua fortuna. Para isso, mostra-se religioso e devoto, porém tudo isso não passava de uma farsa, seu único objetivo era ficar com a herança da tia, já que não havia outro herdeiro natural.

Teodorico pede à tia que lhe pague uma viagem a Paris, mas ela se recusa terminantemente "- Cruzes! - gritou a Sra. D. Patrocínio, horrorizada." (QUEIRÓS, s.d., p. 73), o jovem ainda tenta se justificar dizendo que lá poderia visitar igrejas, mas a Titi, D. Patrocínio, logo rebate dizendo que para ver igrejas em Paris o melhor seria ficar em Portugal, afinal em terras lusitanas há as mais bonitas igrejas e procissões. Aconselhada pelo padre Casimiro, D. Patrocínio decide mandar Teodorico à Terra Santa para que lá pudesse rezar por sua saúde. No primeiro momento, Teodorico lamenta em ter que fazer uma viagem a tão distantes terras, mas logo se anima ao consultar o mapa e ver que até chegar deveria passar por terras "amáveis, femininas e cheias de festas".

O sobrinho de Dona Patrocínio parte e, durante a viagem, enquanto o navio fazia uma parada no Egito, envolve-se com uma inglesa chamada Mary que, depois de muitos momentos íntimos, como recordação, dá-lhe um embrulho com a sua camisa de noite. Chegado à Palestina, Raposão continua a sua vida profana e dissoluta. Na terra santa, tem um sonho no qual se imagina assistindo a todo o processo de condenação e crucificação de Jesus.

Antes de regressar a Portugal, Teodorico lembra-se do pedido da tia e corta uns ramos de um arbusto e tece com estes uma coroa embrulha-a e a coloca em sua bagagem. Entretanto, uma pobre mendiga pede-lhe esmola e ele lhe dá o embrulho, que imaginava conter a camisa de Mary.

Chegando a Lisboa, Teodorico relata à tia todas as penitências e jejuns que ele, supostamente, teria feito durante a peregrinação e no momento oportuno, oferece-lhe o embrulho, dizendo que se tratava de uma preciosa relíquia: a coroa de espinhos de Cristo.

A abertura da suposta relíquia se dá perante uma imensa audiência de sacerdotes e beatas, a pedido do próprio Teodorico, num clima cheio de ansiedade. Porém, para o espanto de todos, quando Dona Patrocínio abre o embrulho, em vez da suposta coroa de espinhos, surge a camisa de noite de Mary, sua amante inglesa.

Depois desse inesperado episódio, Teodorico é expulso da casa da tia e perde toda herança que ambicionava. Para sobreviver, passa a vender relíquias que teoricamente teria trazido da Terra Santa, mas que, na verdade, eram forjadas em seu próprio quarto de hotel. Como disponibilizou grandes quantidades de relíquias no mercado, acaba caindo em descrédito e o negócio acaba arruinado.

Revoltado e indignado com tal situação, discute com a imagem de Cristo numa cruz, que estava em seu quarto, até que julga ver sair do caixilho o próprio Cristo, que o acusa, mostra-lhe o quanto havia errado nas escolhas que fizera. 
Depois disso, arranja um emprego, graças a um amigo do colégio e se casa com Jesuína, irmã desse mesmo amigo. Parece regenerado da hipocrisia que o caracterizava, mas ao saber que o padre Negrão, um dos clérigos que costumava frequentar a casa de Dona Patrocínio, herdara a Quinta onde ele nascera e que este era amante de Amélia, uma mulher com quem Teodorico se relacionara em tempos e que o havia traído, dá-se conta de que tinha perdido a tal fortuna por não ter sido mais radicalmente hipócrita e cínico. Se naquele dia fatídico tivesse tido a coragem de declarar que aquela camisa pertencia a Santa Maria Madalena teria ficado bem visto entre os presentes e herdaria a fortuna da tia.

Ao final de todo esse percurso é que Teodorico resolve escrever suas memórias.

Recuperando alguns episódios para o desenvolvimento da análise, é interessante notar que ao voltar para Portugal, depois de sua grande viagem à Terra Santa, Raposão, assim como era chamado em alguns momentos do romance, sente-se confiante de que seu status diante de sua tia, D. Patrocínio, havia alcançado novos patamares, agora mais elevados que antes, afinal ele havia "rezado" pela saúde dela nessa viagem santa, andou nas ruas onde Jesus caminhara e, o mais importante, supostamente teria lhe trazido uma relíquia sagrada. Teodorico estava tão certo disso que afirma:

Era decerto em mim o deleite de rever, sob aquele céu de janeiro, ao azul e tão fino, a minha Lisboa, com as suas quietas ruas cor de caliça suja, e aqui e além as tabuinhas verdes descidas nas janelas, como pálpebras pesadas de langor e de sono. Mas era, sobretudo, a certeza da gloriosa mudança, que se fizera na minha fortuna doméstica e na minha influência social (QUEIRÓS, s.d., p. 295).

Teodorico não tinha dúvida de que sua herança era certa e maior que pudesse imaginar anteriormente e que, como ele mesmo disse no trecho, tinha "certeza da gloriosa mudança" do juízo que sua tia nutria por ele.

Em seguida, Teodorico ensaia consigo mesmo uma reflexão sobre as questões cruciais do ser humano, perguntando-se sobre sua importância no mundo e no meio em que vivia. Porém, ao contrário do que se poderia esperar, nesse momento Teodorico ainda não está em busca de respostas, mostra-se apenas desejoso de reafirmar as ideias por ele pré-concebidas, tal como se pode constatar no trecho seguinte:

Até aí, que fora eu em casa da senhora Dona Patrocínio? O menino Teodorico que, apesar da sua carta de doutor e das suas barbas de Raposão, não podia mandar selar a égua para ir espontar o cabelo à Baixa, sem implorar licença à Titi... E agora? O nosso Doutor Teodorico, que ganhara, no contacto santo com os lugares do Evangelho, uma autoridade quase pontificial! Que fora eu até aí, no Chiado, entre os meus concidadãos? O Raposito, que tinha um cavalo. E agora? O grande Raposo, que peregrina poeticamente na Terra Santa... (QUEIRÓS, s.d., p. 295-296).

É interessante notar, nesse fragmento, como Teodorico está fechado em si mesmo, imaginando o novo lugar ao qual ocuparia na sociedade de Lisboa. Apesar da opinião pública ser seu foco, não se preocupa de fato com o outro, quer na figura da sociedade lisboeta, quer na figura da tia. Coloca-se sempre em uma posição de superioridade. Tanto é que chega a afirmar na continuação desse fragmento: "Eu sorria, 
humilde". Nessas palavras, Raposão se coloca como personagem de si numa posição distanciada, própria de quem observa sua própria experiência, mas que, em Teodorico, não se produz uma reflexão profícua, aliás, nem reflexão há neste momento.

Por outro lado, Teodorico está tão preocupado com a imagem por ele criada que nem percebe que seu plano poderia estar começando a ser desvendado. Afinal, a primeira frase pronunciada por Titi ao vê-lo é exatamente relativa à observação de que ele estava "queimadinho". Ou seja, para uma pessoa que teria passado a maior parte do tempo em oração não se espera que estivesse bronzeado, assim afirma Patrocínio:

- Ai filho, que queimadinho que vens!...

- Titi, trago-lhe muitas saudades do Senhor...

- Dá-mas todas; dá-mas todas!...

E retendo-me, cingido à dura tábua do seu peito, roçou os beiços frios pelas minhas barbas - tão respeitosamente como se fossem as barbas de pau de imagem de São Teodorico (QUEIRỎS, s.d., p. 296-297).

Diante da constatação de Dona Patrocínio e sem se dar conta do peso que estas palavras imprimia-lhe, Teodorico simplesmente ignora sua tia e apresenta imediatamente uma nova informação, a de que havia trazido "saudades do Senhor...". Assim, sendo Dona Patrocínio "uma beata zelosa das coisas do Senhor", de imediato deixa sua observação para, ansiosamente, querer saber o que lhe havia trazido seu sobrinho que a essa altura assumiria, segundo Teodorico, o lugar de uma personalidade religiosa, a de São Teodorico.

Nos parágrafos seguintes a essas informações, há uma descrição do quanto a tia beata fica curiosa para saber qual era a relíquia que seu sobrinho havia lhe trazido, porém Teodorico Raposo prefere criar um clima de mistério e prepara todo um ambiente especial para o grande momento da entrega: “- Logo se verá. À noite é que se desencaixotam as relíquias... Foi o que me recomendou o patriarca de Jerusalém... Em todo o caso acenda a Titi mais quatro luzes, que até a madeirinha é santa!" (QUEIRÓS, s.d., p. 298). E assim foi aguçando a curiosidade de sua tia, a fim de poder agraciá-la diante de todos os padres e das beatas, de modo a não restar mais nenhuma sombra de dúvida de que ele, Teodorico Raposo, era merecedor de toda a herança da distinta senhora.

É evidente que o Raposo se aproveitou também de toda essa situação para explorar ao máximo a satisfação de D. Patrocínio para com ele, afinal, a todo o momento ela dizia: "- Ai que santo! Ai que santo ouvir estas cousas! Jesus, até dá uns gostinhos por dentro!...” (QUEIRÓS, s.d., p. 284)

Chegada à noite, quando todos estavam reunidos para o grande momento, Teodorico começa a contar o que fez durante a viagem e sobre o quanto rezou por sua Titi. Ao mesmo tempo, D. Patrocínio se admirava diante de tanta fé e piedade manifestada por seu sobrinho e quase não conseguia se conter, tamanha ansiedade. Chegado o momento de maior expectativa, porém, Teodorico, que fez questão da presença dos clérigos e amigos da família, entregou o pacote com a suposta relíquia para a tia e, imediatamente, após a abertura do pacote, ele é desmascarado diante de todos, sendo expulso de casa. A mando de D. Patrocínio, diz Vicência, empregada da casa: 
- Ai, menino! Ai, menino! Se não sai já para a rua, a senhora diz que manda chamar um polícia! [...]

Mal transpus o pátio, a Vicência, cumprindo as ordens sanhudas da Titi, bate-me nas costas com o portão chapeado de ferro - desprezivelmente e para sempre! (QUEIRÓS, s.d., p. 321322)

Por mais que num primeiro momento Teodorico tenha ficado sem saber o que fazer e para onde ir, nada o abalava: "[...] eu não tentara (nem com súplica, nem com explicações, nem com patrocínios) amansar as beatas iras da Titi e repenetrar na sua estima" (QUEIRÓS, s.d., p. 326).

Tendo deixado a casa de sua tia, Teodorico logo arranjou um jeito de sobreviver e tentar "se dar bem na vida", jamais deixando de crer que sua tia poderia vir um dia a perdoá-lo. Como forma de sobrevivência, Teodorico afirma que começou a vender as supostas relíquias que trouxera de Jerusalém, seu primeiro comprador foi Senhor Lino, que Teodorico encontrou no hotel onde se hospedou depois da expulsão e que intermediou as vendas posteriores. "E quando o Senhor Lino saiu do meu quarto, com o frasco do Jordão embrulhado na Nação, eu, Teodorico Raposo, achava-me fatalmente, providencialmente, estabelecido vendilhão de relíquias!” (QUEIRÓS, s.d., p. 325-326).

Teodorico conseguiu vender muitas das supostas relíquias, aliás, nenhum reliquista vendia mais que ele, pois nenhum tinha o privilégio de ter voltado "fresquinho de Jerusalém” (QUEIRÓS, s.d., p. 327), afirma em sua narrativa. Porém, aos poucos, o próprio Teodorico foi percebendo que essas boas vendas não durariam muito tempo, afinal, as relíquias se acabariam e, por outro lado, mesmo forjando-as, como de fato o fez, saturariam o mercado religioso: “[...] bem cedo reconheci que esta profusão de reliquilharia saturara a devoção do meu país. [...] Inquieto, baixei melancolicamente os preços" (QUEIRÓS, s.d., p. 331).

Ao receber a notícia de que sua tia havia falecido, encheu-se de alegria e esperança de que ela o tivesse perdoado e lhe deixado a herança, porém, para sua surpresa e lamento, no testamento ela lhe havia deixado apenas "o óculo que se acha pendurado na sala de jantar [...]” (QUEIRÓS, s.d., p. 315) e distribuiu sua riqueza entre os padres e amigos da igreja. É só a partir daqui que se inicia o processo da anacorese de Teodorico, cujo resultado culminaria na escrita de suas memórias: $A$ Relíquia.

Inconformado com a atitude de sua tia em não lhe deixar a herança, chama contra D. Patrocínio todas as cóleras da natureza. Enfim o sentimento de derrota toma conta de Teodorico Raposo pela primeira vez e, dialogando com Alana Freitas El Fahl, sente-se punido por sua ambição (EL FAHL, 2012, p. 170).

Não consegue acreditar no ocorrido, fica inconformado e, recolhendo-se em seu quarto de hotel, indignado, revoltado e enfurecido, esbravejando consigo mesmo, relata ter visto a sua frente o crucifixo com a imagem de Cristo: "E quando assim esbravejava, esguedelhado - encontrei frigidamente cravados em mim e mais abertos, como gozando a derrota da minha vida, os olhos claros do Cristo crucificado, dentro do seu caixilho com borlas..." (QUEIRÓS, s.d., p. 335).

Vale aqui lembrar que o quarto, segundo Perec na obra Espèces d'espaces, já anteriormente mencionada, delimita o ambiente mais reservado do sujeito, onde o eu se 
recolhe para dentro do seu íntimo, resguardando-se de tudo que o cerca, numa atitude profundamente solitária, abrindo espaço para os devaneios da memória (PEREC, 1974, p. 34).

É no quarto que também Teodorico inicia aquele que classificaremos como o primeiro estágio da anacorese. Nesse espaço, questiona-se acerca dos porquês de sua vida e das consequências de suas atitudes, questiona o porquê da troca dos embrulhos na volta a Lisboa, por que sua tia não lhe deixou a herança e, então, ao ver o Cristo, transfere sua revolta para aquele que seria o empecilho de sua vida farta. Olhando para a imagem de Jesus diz:

- Foste tu! - gritei, de repente iluminando e compreendendo o prodígio. - Foste tu! Foste tu!

E, com os punhos fechados para ele, desafoguei fartamente os queixumes, os agravos do meu coração:

- Sim, foste tu que transformaste ante os olhos devotos de Titi a coroa de dor da tua lenda - na camisa suja da Mary!... e por quê? Que te fiz eu? Deus ingrato e variável? Onde, quando, gozaste tu devoção mais perfeita? Não acudia eu todos os domingos, vestido de preto, a ouvir as missas melhores que te oferta Lisboa? [...] (QUEIRÓS, s.d., p. 335).

Dessa forma, Teodorico num estado de isolamento e conflito, inicia seu processo de anacorese. Assim, o narrador autodiegético passa a expressar seus sentimentos e angústias isoladamente, num momento de recolhimento.

Depois de um bom tempo de desabafo, de acusação e de angústia, para a surpresa de Teodorico, o vidro onde se encontrava o crucifixo se abre e de dentro Jesus "desce" da cruz e discursa, acusando-o de ser ele mesmo, Teodorico Raposo, o causador de tanta desgraça, dizendo:

- Quando tu ias ao alto da graça beijar no pé uma imagem - era para contar servilmente à Titi a piedade com que deras o beijo; porque jamais houve oração nos teus lábios, humildemente no teu olhar - que não fosse para que a Titi ficasse agradada no seu fervor de beata. O deus a que te prostrava era o dinheiro de G. Godinho; e o céu para que teus braços trementes se erguiam - o testamento da Titi [...] Fingiste-te devoto, sendo incrédulo; casto, sendo devasso; caridoso, sendo mesquinho; e simulaste a ternura de filho, tendo só a rapacidade de herdeiro... Tu foste ilimitadamente hipócrita! Mentiste sempre; e só eras verdadeiro [...] quando rogavas a Jesus e à Virgem que rebentassem depressa a Titi. [...] Ora, justiceiramente aconteceu que o embrulho que ofertaste à Titi e que a Titi abriu - foi aquele que lhe revelava a tua perversidade! E isto prova-te... a inutilidade da hipocrisia! (QUEIRÓS, s.d., p. 337-338).

E Jesus termina dizendo ser ele a própria Consciência de Teodorico:

Chamo-me consciência; sou neste instante a tua própria consciência refletida fora de ti, no ar e na luz, e tomando ante teus olhos a forma familiar, sob a qual, tu, mal-educado e pouco filosófico, estás habituado a compreender-me... Mas basta que te ergas e me fites, para que esta imagem resplandecente de todo se desvaneça.

E ainda eu não levantara os olhos - já tudo desaparecera (QUEIRÓS, s.d., p. 339 - Grifo nosso). 
Ou seja, ao colocar-se no estado de isolamento e questionar a sua existência e as consequências de suas próprias ações, Teodorico chega à conclusão, a partir de sua própria consciência que o acusava, de que tudo aconteceu porque não havia feito a coisa correta, afinal,

[...] não poderias seguir muito tempo, junto da titi, mostrando só o lado, vestido de casimiras de domingo, onde resplandecia a virtude; um dia fatalmente chegaria em que ela, espantada, visse o lado despido e natural onde negrejava as máculas do vício... (QUEIRÓS, s.d., p. 338).

Porém ainda não era o fim, ainda havia tempo para mudança, diz Teodorico: "Consultei a minha consciência, que reentrara dentro de mim [...]" (QUEIRÓS, s.d., p. 340), mesmo que essa mudança significasse a negação total da religião e/ou da religiosidade, pois continua dizendo Teodorico:

[...] e bem certo de não acreditar que Jesus fosse filho de Deus e de uma mulher casada de Galileia (como Hércules era filho de Júpiter e de uma mulher casada da Argólia) - cuspi dos meus lábios, tornados para sempre verdadeiros, o resto inútil da oração (QUEIRÓS, s.d., p. 340).

No dia seguinte, ao sair de casa para passear no jardim de São Pedro de Alcântara, encontra um antigo amigo, Crispim, filho de Teles Crispim \& Cia., conversam por um tempo e, durante a conversa assume, diante de Crispim, seu verdadeiro papel de não religioso e depois é apresentado à D. Jesuína, irmã de Crispim. Jesuína tinha trinta e dois anos e era zarolha. Mas como o dote agradou a Teodorico, casa-se com ela e vai trabalhar nos negócios da família. É só depois de todos esses episódios que Teodorico escreve suas memórias.

O Raposo teria passado por conflitos e por longos momentos de reflexão, elementos fundamentais para realizar a escrita de sua bypomnemata, em outros termos, sua escrita de si. É só depois de passar por esse processo do engano ao desengano e de ter tido, teoricamente, uma tomada de consciência, que passa a ser possível escrever suas memórias.

Numa verdadeira mimese da escrita de si, Teodorico assume o papel de anacoreta na medida em que passa pelos estágios de conflito e pela tomada de consciência. Depois disso, apresenta três motivos para a escrita de suas memórias, sua bypomnemata. Primeiro Teodorico diz que passou por uma desilusão incomparável capaz de abalar o seu ser; segundo, afirma que grande mudança aconteceu em sua vida moral e, por fim, afirma escrever "por motivos peculiarmente espirituais", por outro lado, vale destacar que a escrita de si vinculadas aos exercícios espirituais, tal como afirma Teodorico Raposo, pressuporia, em tese, que o narrador autodiegético tivesse aprendido uma lição a partir de seus próprios erros, como se a escrita fosse uma espécie de espurgo dos atos que agora a reflexão crítica os faria condenar, e como se pode claramente perceber em Teodorico, isso não acontece. 
Porém, é inegável que Teodorico realiza de fato a anacorese, mas inverte a sua finalidade tradicional e a esvazia de valores morais, colocando em seu lugar a ideia de eficiência prática, isto é, um tipo de pragmatismo característico da sociedade capitalista na qual estava inserido.

\section{CONSIDERAÇÕES FINAIS}

Buscando encontrar alguns elos entre os aspectos da anacorese nas memórias de personagem de ficção, de Teodorico Raposo, vale destacar que, sumariamente, o processo de anacorese pressupõe um caminho de autoconhecimento, de empatia, de alteridade, ou seja, um cuidado consigo que, inevitavelmente, buscasse um crescimento e aprimoramento do caráter (FOUCAULT, 1985). Em contrapartida, e não incorrendo em desvio epistemológico, o fato de o indivíduo se reconhecer e assumir suas ações não implica dizer que este indivíduo passe por uma transformação pessoal, o que ocorre é que sua transformação sempre haverá de existir, no entanto,' pela tomada de consciência e não, necessariamente, pelas ações práticas, este último aspecto é o que seria o caso de Teodorico Raposo.

Nesses termos, o resultado de todo o processo de anacorese vivido por Teodorico, tal como relatad em suas memórias, o faz descrevê-lo justiicando ser o motivo de sua escrita as questões particularmente espirituais, porém o que está em cena nessa afirmação do narrador é a ironia queirosiana, pois o que toma cabo Teodorico é a instrumentalçização de suas memórias a fim de difundir a mentalidade burguesa ao mesmo tempo em que naturaliza valores e comportamentos descompromissados com a ética religiosa tampouco com a ética laica.

\section{REFERÊNCIAS}

EL FAHAL, Alana Freitas. Singularidades narrativas: uma leitura dos contos de Eça de Queirós. Feira de Santana: UEFS Editora, 2012.

FOUCAULT, Michel. “A escrita de si”. In: O que é um autor? Lisboa: Vega, 2009. . História da Sexualidade: O cuidado de si. Vol. III. Rio de Janeiro: Edições Graal,

1985. - A bermenêutica do sujeito. Curso dado no Collège de France (1981-1982); edição estabelecida por Frédéric Gros, sob a direção de François Ewald e Alessandro Fontana. Trad. Márcio Alves da Fonseca, Salma Tannus Muchail. SP: Martins Fontes, 2006.

McKENZIE, John L. Dicionário Bíblico. 8ª ed. São Paulo: Paulus, 2003.

QUEIRÓS, Eça de. A Relíquia. Porto: Lello \& Irmão, s.d.

SOUSA FILHO, Alípio de. "Foucault: O cuidado de si e a liberdade, ou a liberdade é uma Agonística”. IV Colóquio Internacional de Michel Foucault. Natal: Abril de 2007. 
